\title{
Maturity Onset Diabetes of the Young is Not Necessarily Associated with Autosomal Inheritance: Case Description of a De Novo HFN1A Mutation
}

\author{
Giuseppina Salzano · Stefano Passanisi (D) - Corrado Mammì • \\ Manuela Priolo · Letizia Pintomalli · Lucia Caminiti - Maria F. Messina • \\ Giovanni B. Pajno · Fortunato Lombardo
}

Received: March 11, 2019 / Published online: May 16, 2019

(C) The Author(s) 2019

\begin{abstract}
Maturity onset diabetes of the young (MODY) accounts for up to $4 \%$ of all cases of diabetes in pediatric patients. MODY is usually characterized by autosomal dominant inheritance, impaired insulin secretion, and an average age at diagnosis of $18-26$ years. Mutations in the hepatocyte nuclear factor 1-alpha (HNF1A), glucokinase, hepatocyte nuclear factor 4-alpha, and hepatocyte nuclear factor 1-beta genes are the mutations most frequently observed in cases of MODY. We herein report a case of HNF1A-MODY characterized by an early onset of diabetes. Genetic investigations revealed a de novo heterozygous substitution, N237D
\end{abstract}

Enhanced Digital Features To view enhanced digital features for this article go to https://doi.org/10.6084/ m9.figshare.8063756.

Electronic Supplementary Material The online version of this article (https://doi.org/10.1007/s13300019-0633-3) contains supplementary material, which is available to authorized users.

G. Salzano $\cdot$ S. Passanisi $(\bowtie) \cdot$ L. Caminiti .

M. F. Messina - G. B. Pajno - F. Lombardo

Department of Human Pathology in Adult and

Developmental Age "Gaetano Barresi", University of

Messina, Via Consolare Valeria 1, 98124 Messina,

Italy

e-mail: spassanisi@gmail.com

C. Mammì · M. Priolo · L. Pintomalli

Grande Ospedale Metropolitano, UOSD Genetica

Medica, Reggio Calabria, Italy
(HNF1A c.709A $>$ G), in exon 3 of the HNF1A gene. Our case supports the hypothesis that de novo mutations are more frequent than expected. This recent evidence may suggest that conventional clinical diagnostic criteria for MODY should be revised and personalized according to the individual patient.

Keywords: Genetic testing; Hepatocyte nuclear factor 1-alpha; Hyperglycaemia; Inheritance; MODY; Missense mutation; Next-generation sequencing

\section{INTRODUCTION}

Maturity onset diabetes of the young (MODY) accounts for between 1 and $4 \%$ of all cases of diabetes in children and adolescents [1-4]. MODY is a monogenic form of diabetes characterized by autosomal dominant inheritance, impaired insulin secretion, and an early age at diagnosis-typically under 25 years of age [5, 6]. To date, abnormalities in at least 13 genes on different chromosomes have been described [7]. Molecular genetic testing is needed to confirm a diagnosis of MODY, predict the likely clinical course, define risk for relatives, and determine treatment [8]. Mutations in the hepatocyte nuclear factor 1-alpha (HNF1A), glucokinase (GCK), hepatocyte nuclear factor 4-alpha (HNF4A), and hepatocyte nuclear factor 1-beta 
(HNF1B) genes are the mutations most frequently observed in cases of MODY. HNF1A and GCK mutations are the most common causes of MODY in Caucasian populations $[9,10]$. HNF1A-MODY, also known as MODY 3, prevails in the United Kingdom, the Netherlands, and Germany [11-14]. Its clinical phenotype is heterogeneous and varies according to environmental and/or genetic factors [15]. Generally, HNF1A-MODY manifests itself during the postpubertal and young adult periods; the average age at diagnosis is $18-26$ years. Hyperglycemia is the result of progressive beta-cell function deterioration over time in the absence of clinical signs of insulin resistance. During the early stages of the disease, an oral glucose toleration test (OGTT) can be performed to check for a marked increase in glycemia ( $>5 \mathrm{mmol} / \mathrm{l})$. Rarely, this type of MODY becomes apparent with mild-to-moderate ketoacidosis that is clinically indistinguishable from the onset of type 1 diabetes. Glycosuria is often present and it is related to a low renal threshold, typically lower than $10 \mathrm{mmol} / \mathrm{l}$ [16]. Low-dose sulfonylurea therapy permits effective glycemic control among individuals with HNF1A-MODY by stimulating the existing beta-cell reservoir. An increased risk of microvascular and macrovascular complications in HFN1A-MODY patients has recently been highlighted $[17,18]$.

In the case reported in the present paper, we identified a de novo heterozygous substitution, N237D (HNF1A c.709A $>$ G), in exon 3 of HNF1A in a MODY 3 patient. This mutation was already known to be a MODY pathogenic variant according to the VarSome database. Written informed consent was obtained from the patient's parents for the publication of this case report.

\section{CASE PRESENTATION}

A 10-year-old female child, the third born to nonconsanguineous parents, was admitted to our clinic with a recent history of polyuria, polydipsia, and headache. The family history was negative for any form of diabetes, but positive for another autoimmune disease (her mother was affected by Hashimoto's thyroiditis). At the age of 6 years she had been surgically treated for hepatic cystic echinococcosis. She was in a good clinical state at admission, and a general examination showed no abnormalities. A physical examination evidenced normal growth parameters and blood pressure. Laboratory tests showed the following results: glycemia $21.4 \mathrm{mmol} / \mathrm{l}$, glycated hemoglobin (HbA1c) $94 \mathrm{mmol} / \mathrm{mol}$ (normal value 20-48 $\mathrm{mmol} / \mathrm{mol}$ ). Her acid-base balance was normal ( $\mathrm{pH} 7.39$, serum bicarbonate $23 \mathrm{mmol} / \mathrm{l}$ ). Ketonemia and ketonuria were negative. Plasma basal C-peptide and stimulated C-peptide after an intravenous glucagon load were, respectively, $\quad 1.07 \mathrm{ng} / \mathrm{ml}$ (normal value $1.0-3.0 \mathrm{ng} / \mathrm{ml}$ ) and $2.52 \mathrm{ng} / \mathrm{ml}$ (normal value $3.0-9.0 \mathrm{ng} / \mathrm{ml}$ ). Abdominal ultrasound was negative for hepatic lesions and/or renal abnormalities. Multiple daily insulin treatment was started, with an initial total insulin dosage of $0.8 \mathrm{IU} / \mathrm{kg}$, insulin lispro at meals, and insulin glargine at bedtime. Tests for antibodies against insulin, glutamate decarboxylase (GAD), tyrosine phosphatase (IA2), islet cells (ICA), and zinc transporter 8 (ZnT8) were all negative. HLA did not predispose the patient to type 1 diabetes. During the first 6 months of follow-up she maintained her HbA1c values above $53 \mathrm{mmol} / \mathrm{mol}$. Her glycemic control was not optimal since it was characterized by broad glycemic variability. On the suspicion of monogenic diabetes, genetic testing was performed. The genetic analysis revealed a de novo heterozygous substitution, N237D (HNF1A c.709A $>G$ ), in exon 3 of the HNF1A gene in the proband. This substitution was not present in her parents. The biological relationship of the proband to her parents was confirmed by microsatellite analysis.

Once HNF1A-MODY had been diagnosed, we suspended insulin therapy and started treatment with gliclazide at $1.4 \mathrm{mg} / \mathrm{kg}$. We observed a prompt improvement in the patient's glycemic control after the first few days of the new therapeutic approach. During the subsequent 6 months of follow-up, her mean glycosylated hemoglobin was $44 \mathrm{mmol} / \mathrm{mol}$. 


\section{DISCUSSION}

The HNF1A gene is located at chromosome $12 q 24$, comprises 10 exons that span $23,790 \mathrm{bp}$, and encodes a 631-amino-acid protein which is expressed in many tissues such as the liver, kidney, and pancreas [19]. In pancreatic beta cells, HNF1A plays a regulatory role in the expression of several genes involved in glucose metabolism and transport, such as glucose transporter 2 (GLUT2) and pyruvate kinase $[20,21]$. One of the first direct studies of human islets from an individual with a heterozygous missense variant in the HNF1A locus confirmed that loss-of-function variants of HNF1A lead to insulin-insufficient diabetes not through a significant loss of beta-cell mass but rather by impacting beta-cell transcriptional regulatory networks, resulting in the impairment of betacell pathways that are needed for a normal insulin response to glucose [22]. Heterozygous mutations of HNF1A that cause diabetes were first identified in 1996, and more than 400 different mutations have since been described [23]. These mutations include missense and nonsense mutations, insertions and duplications, deletions, insertion/deletions, promoter region mutations, and splice site mutations [24]. These mutations occur throughout the gene, but they are mainly found in exon 2 (0.33 mutations per nucleotide) and in exon 4 (0.28 mutations per nucleotide). A high proportion of the mutations, particularly missense mutations, involve the dimerization and DNA-binding domains, which seem to be less tolerant of minor structural changes [25]. The type and the location of the mutation seem to be linked to the age at diabetes diagnosis. Mutations involving the first six exons are correlated with an earlier diagnosis (median age of 18 years) than mutations located in either exons 8-10 or the transactivation domain (median age of 30 years) [26]. Patients with truncating mutations are diagnosed at an average age of 20 years regardless of the location of the mutation within the HNF1A gene $[27,28]$.

The gold standard method of screening for mutations is sequence analysis of the coding regions and conserved splice sites [29]. In patients with a very specific clinical phenotype, Sanger sequencing, also called the chain termination method, may be sufficient to identify abnormalities of the selected gene [4]. The recent introduction of targeted next-generation sequencing (NGS) - which permits the sequencing of gene collections, exomes, or even whole genomes-has led to an increase in the number of patients diagnosed with monogenic diabetes [30].

To our knowledge, the c.709A > G HNF1A missense mutation has only been identified in one family before [31]. As regards the clinical aspects of the mutation, our patient was diagnosed at the age of 10 years. Diabetes onset was characterized by classic symptoms: hyperglycemia and a HbA1c value of $94 \mathrm{mmol} / \mathrm{mol}$ in the absence of ketoacidosis. The switch from insulin to sulfonylurea treatment was successful and led to good glycemic control. This clinical course demonstrated that this type of mutation seems to be related to a very early deterioration of beta-cell function, which can lead to the onset of diabetes during the first decade of life. The prompt response to gliclazide treatment is in accord with the evidence of sulfonylurea sensitivity in the majority of HNF1A diabetic patients [32].

De novo MODY mutations are conventionally considered rare. The American Diabetes Association and various clinical centers for monogenic diabetes have created and published general guidelines, recommendations, and algorithms which suggest that DNA analysis should be performed only if patients have a family history of at least two generations with hyperglycemia or diabetes [7, 33-35]. Nevertheless, some recent epidemiological studies have demonstrated that de novo mutations of the major MODY genes could be more frequent than previously assumed. Stanik et al. described 11 de novo mutations of GCK, HNF1A, and HNF4A in 150 probands $(16.3 \%$ of the entire cohort of 922 patients) who fulfilled all of the MODY criteria except for the family history of diabetes or hyperglycemia. Four of these de novo mutations involved the HNF1A gene [36]. Yorifuji et al. analyzed the four major MODY genes in a cohort of 263 Japanese patients with early-onset, non-obese, MODY-like diabetes. 
Those authors discovered that $13.8 \%$ of the patients were mutation positive and did not have affected parents. Five of the 19 reported de novo mutations are of the HNF1A gene [37]. This recent evidence could cast doubt on the validity of one of the clinical characteristics most commonly used for MODY diagnosis-a family history of at least two unilateral consecutive generations with diabetes or hyperglycemia. Therefore, in order to minimize misdiagnosis, clinical diagnostic criteria should be revised and personalized according to the individual patient.

\section{CONCLUSION}

Our case supported the hypothesis that de novo mutations are not as rare as expected. More epidemiological studies, especially those incorporating NGS investigations, should be implemented as a means to identify the clinical features and biomarkers that are typical of MODY patients, allowing the development of clinical approaches to the selection of patients for testing that have the optimal combination of sensitivity and specificity.

\section{ACKNOWLEDGEMENTS}

Funding. No funding or sponsorship was received for this study or the publication of this article. The article processing charges were funded by the authors.

Authorship. All named authors meet the International Committee of Medical Journal Editors (ICMJE) criteria for authorship for this article, take responsibility for the integrity of the work as a whole, and have given their approval for this version to be published.

Disclosures. Giuseppina Salzano, Stefano Passanisi, Corrado Mammì, Manuela Priolo, Letizia Pintomalli, Maria Francesca Messina, Lucia Caminiti, Giovanni Battista Pajno and Fortunato Lombardo have nothing to disclose.
Compliance with Ethics Guidelines. Written informed consent was obtained from the patient's parents for the publication of this case report.

Open Access. This article is distributed under the terms of the Creative Commons Attribution-NonCommercial 4.0 International License (http://creativecommons.org/licenses/ by-nc/4.0/), which permits any noncommercial use, distribution, and reproduction in any medium, provided you give appropriate credit to the original author(s) and the source, provide a link to the Creative Commons license, and indicate if changes were made.

\section{REFERENCES}

1. Pettitt DJ, Talton J, Dabelea D, et al. Prevalence of diabetes mellitus in U.S. youth in 2009: the SEARCH for diabetes in youth study. Diabetes Care. 2009;2014(37):402-8.

2. Mozzillo E, Salzano G, Barbetti F, et al. Survey on etiological diagnosis of diabetes in 1244 Italian diabetic children and adolescents: impact of access to genetic testing. Diabetes Res Clin Pract. 2015;107:15-8.

3. Johansson BB, Irgens HU, Molnes J, et al. Targeted next-generation sequencing reveals MODY in up to $6.5 \%$ of antibody-negative diabetes cases listed in the Norwegian Childhood Diabetes Registry. Diabetologia (Germany). 2017;60:625-35.

4. Misra S, Owen KR. Genetics of monogenic diabetes: present clinical challenges. Curr Diab Rep. 2018;18:141.

5. Tattersall RB. Mild familial diabetes with dominant inheritance. Q J Med. 1974;43:339-57.

6. Anık A, Çatlı G, Abacı A, Böber E. Maturity-onset diabetes of the young (MODY): an update. J Pediatr Endocrinol Metab. 2015;28:251-63.

7. American Diabetes Association. Classification and diagnosis of diabetes: standards of medical care in diabetes-2018. Diabetes Care. 2018;41:S13-27.

8. Ellard S, Bellanné-Chantelot C, Hattersley AT, European Molecular Genetics Quality Network (EMQN) MODY Group. Best practice guidelines for the molecular genetic diagnosis of maturity-onset 
diabetes of the young. Diabetologia. 2008;51:546-53.

9. Pihoker C, Gilliam LK, Ellard S, et al. Prevalence, characteristics and clinical diagnosis of maturity onset diabetes of the young due to mutations in HNF1A, HNF4A, and glucokinase: results from the SEARCH for Diabetes in Youth. J Clin Endocrinol Metab. 2013;98:4055-62.

10. Thanabalasingham G, Owen KR. Diagnosis and management of maturity onset diabetes of the young (MODY). BMJ. 2011;343:d6044.

11. Shields BM, Hicks S, Shepherd MH, Colclough K, Hattersley AT, Ellard S. Maturity-onset diabetes of the young (MODY): how many cases are we missing? Diabetologia. 2010;53:2504-8.

12. Kyithar MP, Bacon S, Pannu KK, et al. Identification of HNF1A-MODY and HNF4A-MODY in Irish families: phenotypic characteristics and therapeutic implications. Diabetes Metab. 2011;37:512-9.

13. Losekoot $\mathrm{M}$, Broekman AJ, Breuning $\mathrm{MH}$, de Koning EJ, Romijn JA, Maassen JA. Molecular diagnosis on indication of maturity onset diabetes of the young; results from 184 patients. Ned Tijdschr Geneeskd. 2005;2005(149):139-43.

14. Toaima D, Nake A, Wendenburg J, et al. Identification of novel GCK and HNF1A/TCF1 mutations and polymorphisms in German families with maturity-onset diabetes of the young (MODY). Hum Mutat. 2005;25:503-4.

15. Galán M, García-Herrero CM, Azriel S, et al. Differential effects of HNF-1alpha mutations associated with familial young-onset diabetes on target gene regulation. Mol Med. 2011;17:256-65.

16. Stride A, Ellard S, Clark P, et al. Beta-cell dysfunction, insulin sensitivity, and glycosuria precede diabetes in hepatocyte nuclear factor-1alpha mutation carriers. Diabetes Care. 2005;28:1751-6.

17. Steele AM, Shields BM, Shepherd M, Ellard S, Hattersley AT, Pearson ER. Increased all-cause and cardiovascular mortality in monogenic diabetes as a result of mutations in the HNF1A gene. Diabet Med. 2010;27:157-61.

18. Szopa M, Osmenda G, Wilk G, et al. Intima-media thickness and endothelial dysfunction in GCK and HNF1A-MODY patients. Eur J Endocrinol. 2015;172:277-83.

19. Pontoglio M, Barra J, Hadchouel M, et al. Hepatocyte nuclear factor 1 inactivation results in hepatic dysfunction, phenylketonuria, and renal Fanconi syndrome. Cell. 1996;84:575-85.
20. Odom DT. Control of pancreas and liver gene expression by HNF transcription factors. Science. 2004;303:1378-781.

21. Bacon S, Kyithar MP, Schmid J, et al. Serum levels of pancreatic stone protein (PSP)/reg1A as an indicator of beta-cell apoptosis suggest an increased apoptosis rate in hepatocyte nuclear factor 1 alpha (HNF1AMODY) carriers from the third decade of life onward. BMC Endocr Disord. 2012;12:13.

22. Haliyur R, Tong X, Sanyoura M, et al. Human islets expressing HNF1A variant have defective $\beta$ cell transcriptional regulatory networks. J Clin Investig. 2019;129:246-51.

23. Yeung RO, Hannah-Shmouni F, Niederhoffer K, Walker MA. Not quite type 1 or type 2, what now? Review of monogenic, mitochondrial, and syndromic diabetes. Rev Endocr Metab Disord. 2018;19:35-52.

24. Ellard S, Colclough K. Mutations in the genes encoding the transcription factors hepatocyte nuclear factor 1 alpha (HNF1A) and 4 alpha (HNF4A) in maturity-onset diabetes of the young. Hum Mutat. 2006;27:854-69.

25. Bjorkhaug L, Sagen JV, Thorsby P, Sovik O, Molven A, Njolstad PR. Hepatocyte nuclear factor-1 alpha gene mutations and diabetes in Norway. J Clin Endocrinol Metab. 2003;88:920-31.

26. Colclough K, Saint-Martin C, Timsit J, Ellard S, Bellanne-Chantelot C. Clinical utility gene card for: maturity-onset diabetes of the young. Eur J Hum Genet. 2014;22(9).

27. Ellard S, Thomas K, Edghill EL, et al. Partial and whole gene deletion mutations of the GCK and HNF1A genes in maturity-onset diabetes of the young. Diabetologia. 2007;50:2313-7.

28. Bellanne-Chantelot C, Carette C, Riveline JP, et al. The type and the position of HNF1A mutation modulate age at diagnosis of diabetes in patients with maturity-onset diabetes of the young (MODY)3. Diabetes. 2008;57:503-8.

29. Harries LW, Ellard S, Stride A, Morgan NG, Hattersley AT. Isomers of the TCF1 gene encoding hepatocyte nuclear factor-1 alpha show differential expression in the pancreas and define the relationship between mutation position and clinical phenotype in monogenic diabetes. Hum Mol Genet. 2006;15:2216-24.

30. Ellard S, Lango Allen H, De Franco E, et al. Improved genetic testing for monogenic diabetes using targeted next-generation sequencing. Diabetologia. 2013;56:1958-63. 
31. Colclough K, Bellanne-Chantelot C, Saint-Martin C, Flanagan SE, Ellard S. Mutations in the genes encoding the transcription factors hepatocyte nuclear factor 1 alpha and 4 alpha in maturity-onset diabetes of the young and hyperinsulinemic hypoglycemia. Hum Mutat. 2013;34:669-85.

32. Shepherd M, Shields B, Ellard S, Rubio-Cabezas O, Hattersley AT. A genetic diagnosis of HNF1A diabetes alters treatment and improves glycaemic control in the majority of insulin-treated patients. Diabet Med. 2009;26:437-41.

33. Naylor R, Philipson LH. Who should have genetic testing for maturity-onset diabetes of the young? Clin Endocrinol (Oxf). 2011;75:422-6.

34. Pinelli M, Acquaviva F, Barbetti F, et al. Identification of candidate children for maturity-onset diabetes of the young type 2 (MODY2) gene testing: a seven-item clinical flowchart (7-iF). PLoS One. 2013;8:79933.

35. Carroll RW, Murphy R. Monogenic diabetes: a diagnostic algorithm for clinicians. Genes (Basel). 2013;4:522-35.

36. Stanik J, Dusatkova $\mathrm{P}$, Cinek $\mathrm{O}$, et al. De novo mutations of GCK, HNF1A and HNF4A may be more frequent in MODY than previously assumed. Diabetologia. 2014;57:480-4.

37. Yorifuji T, Higuchi S, Kawakita R, et al. Genetic basis of early-onset, maturity-onset diabetes of the young-like diabetes in Japan and features of patients without mutations in the major MODY genes: dominance of maternal inheritance. Pediatr Diabetes. 2018;19:1164-72. 